\title{
Problems in staffing of emergency departments
}

\author{
R. A. ELSON \\ M.B., B.Ch., F.R.C.S. \\ Consultant Orthopaedic Surgeon, \\ Northern General Hospital, Sheffield
}

Previous speakers have recounted most of the difficulties at present being experienced in the staffing of casualty departments and these have been further amplified in discussion. It would seem more valuable, rather than re-iterating these, to put forward some possible solutions and criticize some of the solutions suggested by others.

Before a clear decision can be reached it will be necessary to reconcile the often conflicting views of interested parties. The Department of Health, which has the job of developing solutions which may be applied nationally, relies for its advice on the profession. Sometimes, the previous speakers have put forward view points from positions of isolation and it is very necessary to attempt to reconcile these. At this stage it is necessary to state that the British Orthopaedic Association has failed to develop a trouble-free casualty service, and while this may not be entirely their fault, it is their responsibility because they accepted this burden. The Casualty Surgeons Association (of which I am a member) has to some extent exploited the situation in persuading the profession and the Department of Health to proceed with the creation of consultant casualty surgeon posts which in some instances might involve the appointment of existing medical assistants.

\section{Consultant responsibility}

What do we mean by 'consultant'? This title involves the possession of certain qualities; for example, the ability to pass examinations, the importance of which we should not minimize, for it is essential that a Consultant should be able to retain in his mind a large number of facts and to recall them in various combinations at a moment's notice; this is what he is doing all the time when dealing with patients and staff. The consultant shares with the general practitioner ultimate clinical responsibility, but he is a person who receives whereas the general practitioner is one who habitually refers when necessary-this concept will be further developed when I discuss the need in the casualty department for a casualty consultant. The automatic upgrading of medical assistants to consultant status in the absence of the essential qualifications (academic or personality) would be a tremendous error.
I believe that we need specialists in casualty work in the same way as we are likely in the future to have specialists in general practice. The function of such a doctor will be to diagnose and then to treat those patients who should remain the responsibility of the casualty department. The remainder must be referred to the appropriate department, including general practice. The consultant casualty surgeon must have the knowledge, the ability and the personality to organize his department and, in particular, to teach in that department effectively. The Department of Health, faced with the desperate need to improve staffing, have seized on the concept of the casualty surgeons, and is proposing to start a 'pilot scheme' at a time when there are just not sufficient candidates of adequate calibre to fill the posts. This makes the likelihood of failure great and in turn will bring the whole concept into disrepute. Further, in the individual case where an appointment is made, this can hardly be termed a pilot appointment.

\section{The casualty specialist}

What attraction can be offered to a person of the calibre required (i.e. one who should be able to achieve consultant status in whatever specialty he has chosen to follow) in order to persuade him to be willing to refer all the more challenging patient material to another authority? One strong motive would be an emphasis on teaching. Adequate teaching is only possible when a consultant is prepared to spend most of his time physically in the department. An orthopaedic surgeon concerned with clinics and operating, and other consultants giving but a small proportion of their time to the department, would not be able to provide the standard of education which will be necessary before the Royal College of General Practitioners agrees to channel its trainees through a period in emergency surgery.

The casualty consultant must have a knowledge of the whole spectrum of casualty work. The system of segregating patients with medical, surgical and traumatic emergencies may work well in a large, well-staffed teaching unit, as it does in Oxford, but we are more concerned with finding a pattern for the middle size of casualty department frequently found in less attractive parts of England. It will be 
necessary for such consultants to possess a diploma comparable with the Fellowship, and membership possibly awarded by the Royal Colleges conjointly. His period of training should be comparable with the other specialties. However, the ability to teach and to train should be one of the chief criteria for appointment and his responsibility should be such that he should be able to obtain a merit award Improvements in the level of teaching would, in their turn, lead to a new interest amongst general practitioners in the provision of a service to the community for minor injury and emergencies, a service which will be facilitated by the development of group practices.

\section{Staffing}

By themselves, the appointment of casualty surgeons along the lines suggested, will achieve nothing in terms of the service needs of the departments. They will, however, increase the attractiveness of the senior house officer posts (which will continue to provide the bulk of medical man-power in casualty) because they provide an immediate consultant caring for the interest of the trainee doctors. The senior house officer posts can only be filled with doctors of high enough calibre if a form of medical conscription is introduced in addition to that started by the Royal College of Surgeons in 1944 when it introduced a period into casualty into the requirements for the FRCS. This should largely form part of the trainee programme for general practice and, undoubtedly, experience in an emergency department will be, provided it is properly cared for consultant-wise, of immense value-after all, it comprises the acute aspects of general practice. The expansion in the universities at present taking place will produce a $70 \%$ increase in the number of medical students qualifying over the next 10 years so that there is a probability that the present staffing difficulties will be eased in the future.

\section{Conclusions}

I hope I have made out the case for the appointment of specialists in emergency medicine to perform three functions in the casualty departments of the future. They will have a clinical function limited to diagnosis and the initiation of treatment along the lines laid down by their consultant colleagues in the other specialties, they will have administrative control of the departments and, most important of all, they will have a recognized teaching function with affiliation to either a university or one of the colleges. It is unlikely, though not impossible, that this post could be filled adequately by an orthopaedic or general surgeon who will be able to spend only part of his time in the department, and whose natural bent would be to receive rather than refer cases. The attraction of people of true consultant ability to these posts would necessitate a proper training programme with a diploma and a recognition of the status and importance of the specialty. With adequate standards of teaching established, there will be great advantages to both individual doctors and the community if a period in an emergency department formed part of the training of all general practitioners and of trainees in a number of the hospital specialities. Institution of this pattern of staffing cannot begin in much less than 5 years, but it is far preferable to wait this time and establish a pattern of high quality than to proceed, as is being done, with an experiment in staffing which seems unlikely to provide the type of solution needed (Elson, 1971).

\section{Reference \\ Elson, R.A. (1971) The medical staffing of British accident and emergency departments. British Journal of Hospital Medicine, 6, 161 .}

\section{Discussion}

DR CULL: From the GP's point of view training in casualty departments would be ideal, but there must be teaching: at present in the Birmingham casualty departments there is insufficient. The idea of GPs spending a night on call sleeping in a health centre was brought up at a Local Medical Committee some years ago and I remember it being 'shot down in flames'.

However, I do feel that the pendulum has probably swung too far in favour of the family doctor being able to completely abrogate his round-the-clock responsibility for patients. A middle course should be steered between a 24-hr day, 7-day week commitment and the ability to hive off all night and weekend work onto locums.
MR ELSON: I agree that the present general pracitioners will be most unwilling to take on any further responsibilities towards their patients, but that I believe that proper training together with education at undergraduate level could cause a change in attitudes.

The new structure proposed will take 8-10 years to come to fruition and meanwhile it may be necessary to pay junior staff to bridge the gap.

MR MUlHOllaND: Mr Elson, how will you create a climate of opinion in which people will be encouraged to enter the proposed specialty of emergency medicine?

MR ELSON: The logistics of this will be complex. The first step will be to obtain the profession's consent in 
principle following which the Department of Health will have to establish the grade. A diploma will need to be created. At the same time, staffing of the casualty departments will have to be adequate, and this will involve increased expenditure over some years.

Mr CARo: I would like to agree with Mr Elson when he says that it is quite wrong to appoint people who are not fully capable of doing the work of a specialist to consultant posts in emergency medicine. It is neither the Department of Health's nor the casualty surgeon's intention that this should happen. I think he underestimates the size of the pool of available candidates, for of the two posts of this sort recently advertised, there were about twenty applicants for the one, and over forty for the other. Out of these at least five or six men must surely have been suitable. It is time to say that a number of casualty surgeons are doing this work from second choice. Several specialties have started in this way-not the least of them being orthopaedics. 'I could not be a general surgeon so I took up orthopaedics.'

Mr ELSON: Five or six good quality candidates from a field of fifty or sixty is not ideal. I wonder how much of the casualty surgeons' present strong position is due to the fundamental correctness of their approach and how much is due to general difficulties in staffing at the senior house officer level.

MR WAINWRIGHT: Continued patient care is a very important part of medicine for many people. Will you be able to rely on these new consultants passing on their patients when necessary, or do you envisage them having beds of their own?

MR ELSON: The consultant will be involved in teaching general practitioners how and when to refer on patients, and I think the great responsibility he will have to instruct other people to 'do as I do' will act as a safeguard.

MR O'CONNOR: I wonder how many people in the audience would be prepared to accept a post of this nature? Could those who would show their hands? (Eight people indicated that they would, three of these being orthopaedic trainees. The point was made that progressive patient care is coming in hospitals and that this is likely to bring a change in attitudes.)

MR ROSE: A number of sacred cows are bedevilling discussion of the subject of casualty services. One of these is the concept that all consultants are equal. Mr Elson cannot expect that casualty consultants will be more likely to get merit awards than other consultants but it is reasonable to consider some form of extra financial incentive.

Mr SPIVEY: I would like to question Mr Elson on how he proposes to train the emergency consultants. Do you see the normal ladder of progression from house surgeon to senior registrar working in this case? How do you resolve the paradox that the trainer will be teaching the trainee on patients many of whom will be referred to someone else for treatment?

MR ELSON: If general practitioners are to become specialists in their subject as is envisaged, then they must expect to do a full training in it in the same way that other specialists do.

Those who wished to become casualty consultants would then concentrate on the acute aspects of medical care. They must be able to teach by example the proper selection of patients, treating some and referring others.

Mr SPIVEY: Surely, to achieve a consultant level of knowledge for all the conditions such a consultant is likely to have to diagnose and treat might take years in training-perhaps taking him up to the age of 65 !

MR ELSON: It is not intended to make these consultants specialists in every specialty - they will have special training and knowledge of the acute aspects of casualty work, administration and teaching. After rotational posts similar to those for general practice vocational training (but including anaesthetics and domicilary practice) they would become senior registrars in emergency medicine in a first class casualty department. 